\title{
QTc prolongation - a predictor for autonomic neuropathy in diabetic patients
}

\author{
Kanwar GS ${ }^{1}$, Paikra $S^{2}$, Basan $K^{3}$ \\ ${ }^{1}$ Dr.Gopal Singh Kanwar, Assistant Professor, Department of Medicine, ${ }^{2}$ Dr. Shashi Paikra, Demonstrator, Department \\ of Anatomy, ${ }^{3}$ Dr. Kamaljit Basan, Demonstrator, Department of Anatomy. All affiliated to CIMS, Bilaspur, CG, India
}

Address for Correspondence: Dr. Gopal Singh Kanwar. Email:drgopalskanwar@ rediffmail.com

\begin{abstract}
Introduction: ECG is an important tool to assess the electrical activity of the heart. It is like any other investigation which can be done on bedside. In this study we have assessed the prolongation of QT interval (QTc), which is a marker for assessment of autonomic neuropathy (AN), in diabetic patients. The probability of autonomic neuropathy is high if the QT interval is prolonged. Material and Methods: All patients of Type I and Type II Diabetes Mellitus of various age groups studied in the period of 1 year. Results: As per the discussion QTc can be considered as the predictor of autonomic neuropathy (AN) in a patient if it is prolonged (>440 msec.). Conclusion: Instead of doing the tests for AN which are more cumbersome a simple QTc can predict AN in a patient. The thumb rule tests definitely stand to grade and assess the AN in a patient, but QTc is inexpensive, more tolerated and easier tool to label the patient as having AN.
\end{abstract}

Keywords: QTc interval, Type I Diabetes, Type II Diabetes Mellitus, Autonomic Neuropathy, ECG.

\section{Introduction}

Diabetes is one of the most ancient diseases known to man. The magnitude of population that suffers from this disease along with the morbidity and mortality associated with the illness has enticed a galaxy of research workers.

The Earliest description dates around $400 \mathrm{BC}$ as Honey Urine, and was around 3000 years ago. Diabetes involves cardiovascular system in various ways especially the coronary arteries, to develop the Coronary artery disease (CAD), the silent myocardial infarction (MI) \& dilated cardiomyopathy (DCM).Cardiac autonomic nerves have the sympathetic and parasympathetic components, both of which can be involves in case of Diabetes.In the ECG the QT interval measures the ventricular activity and is the time period from starting of the $\mathrm{Q}$ wave till the end of the $\mathrm{T}$ wave. The correction of the QT interval is done in comparison with the heart rate and is called the QTc. This requires the use of the Bazett's formula [1]. Prolongation of QTc is the marker for sudden cardiac death [2]. Similar studies have been done in this regard [3][4]. Central respiratory depression and increased frequency of sudden death is also documented [5]. Cough reflex threshold, a vagus mediated respiratory protective

Manuscript received: $23^{\text {rd }}$ May 2015

Reviewed: $4^{\text {th }}$ June 2015

Author Corrected: $20^{\text {th }}$ June 2015

Accepted for Publication: $26^{\text {th }}$ June 2015 reflex was raised suggesting the denervation of respiratory tract [6]. Hence the use of respiratory depressants and anesthetics in diabetes should be judicious. Other tests used are Valsalva, Deep Breath test, 30 : 15 ratio, Postural hypotension and SHGT (Ewing et al 1920), are difficult from the point of view of the patient's cooperation. QTc can easily be performed, is patient friendly, nearly $100 \%$ specific [7]. QTc is a valuable bed-side tool for the assessment of the patient, their routine evaluation and timely intervention. Refer to all the studies.

\section{Aims and Objectives}

1. To study the Frequency of QTc prolongation in Diabetes subjects.

2. To study the relationship between QTc prolongation and Cardiac autonomic neuropathy in diabetic subjects.

3. To study the relationship of cardiac autonomic neuropathy with duration and type of diabetes mellitus.

4. To study the relationship between QTc prolongation with degree of Cardiac autonomic neuropathy in diabetic subjects.

5. To study the relationship between QTc prolongation with other complications of Diabetes Mellitus. 


\section{Materials and Methods}

1. 50 Patients were selected, exclusive of age, sex, type and duration of Diabetes.

2. Time frame of 1 year from July 2013 to June 2014 .

3. Selection criteria included the Inclusion Criteria and Exclusion Criteria as Under:

a. Inclusion criteria:

i. All cases of Type I DM and Type II DM admitted in the Hospital.

ii. All cases of various age groups.

b. Exclusion Criteria:

i. Patients with anti arrythmic drugs.

1. Class 1 A - Quinidine, Dysopyramide, Procainamide, Tricyclic antidepressants, Phenothiazines.

2. Class III - Amiodarone, Sotalol.

3. Hypothermia. [8]

4. Intracranial Bleed.

5. Hypocalcaemia.

6. Acute Myocarditis (Clinically)

7. Acute myocardial Infarction.

8. Hypertrophic Cardiomyopathy.

9. Advanced or complete AV block.

10. Heriditary -

a. Jervell-Lange Nelson Syndrome.

b. Romano-ward Syndrome.
4. History:

Detailed clinical history was taken and more emphasis on Symptoms of autonomic Neuropathy (Postural Dizziness, Impotence, Gustatory Sweating, Atonic Bladder, Gasteroperesis, Constipation, Diabetic Diarrhoea etc.)

\section{Clinical Examination :}

Detailed clinical examination was done and Cardiac Dysautonomia assessment was done by non-invasive response to autonomic function tests. That includes Valsalva Ratio 30:15, Diastolic BP rise with sustained hand grip and postural hypotension, [9].

\section{Tests:[9]}

a. Valsalva Ratio: (Heart rate response to Valsalva maneuver)

b. Deep Breath test: (Heart rate (R-R interval ) variation during deep breathing)

c. 30:15 ratio: (Immediate Heart rate response to standing).

d. Postural hypotension: (Blood pressure response to standing)

e. SHGT: (Blood pressure response to sustained handgrip)

\section{Scoring}

Done as per criteria of A Score of 2 or more denoted definite cardiac autonomic neuropathy [4]

\begin{tabular}{|l|l|l|l|}
\hline Name of the test & Normal (0) & Borderline(1) & Abnormal (2) \\
\hline $\begin{array}{l}\text { Valsalva ratio } \\
\text { (Longest R-R/shortest R-R) }\end{array}$ & $\geq 1.21$ & $1.11-1.20$ & $\leq 1.10$ \\
\hline $\begin{array}{l}\text { Deep Breath Test } \\
\text { (E:I ratio, beat / minute) }\end{array}$ & $\geq 15$ & $11-15$ & $\leq 10$ \\
\hline $\mathbf{3 0}: \mathbf{1 5}$ ratio & $\geq 1.04$ & $1.01-1.03$ & $\leq 1.0$ \\
\hline $\begin{array}{l}\text { Postural Hypotension } \\
\text { fall in systolic BP on standing, (mm of Hg)) }\end{array}$ & $\leq 10$ & $11-29$ & $\geq 30$ \\
\hline $\begin{array}{l}\text { SHGT } \\
\text { (Increase in diastolic BP on sustained hand grip } \\
(\mathrm{mm} \text { of Hg)) }\end{array}$ & $\geq 16$ & $11-15$ & $\leq 10$ \\
\hline
\end{tabular}




\section{Gradation}

Donefrom 0-IV, and Grade I onwards being definite autonomic neuropathy[10].

\begin{tabular}{|c|c|c|c|}
\hline Grade & Particulars & Result of parasympathetic tests & $\begin{array}{l}\text { Result of sympathetic } \\
\text { tests }\end{array}$ \\
\hline 0 & $\begin{array}{l}\text { Normal sympathetic and } \\
\text { Parasympathetic functions }\end{array}$ & All normal or one borderline & Normal \\
\hline $\mathrm{I}$ & Mild parasympathetic dysautonomia & $\begin{array}{l}\text { One abnormal or two or more } \\
\text { borderline }\end{array}$ & Normal \\
\hline II & $\begin{array}{l}\text { Moderate parasympathetic } \\
\text { dysautonomia }\end{array}$ & $\begin{array}{l}\text { Two abnormal or one abnormal } \\
\text { and two borderline }\end{array}$ & Normal \\
\hline III & $\begin{array}{l}\text { Severe parasympathetic } \\
\text { dysautonomia }\end{array}$ & more than two abnormal tests & Normal \\
\hline IV & $\begin{array}{l}\text { Combined parasympathetic and } \\
\text { sympathetic dysautonomia }\end{array}$ & Any parasympathetic abnormality & $\begin{array}{l}\text { One abnormal or two } \\
\text { borderline. }\end{array}$ \\
\hline
\end{tabular}

9. QTc:

a. Subject with definite cardiac autonomic neuropathy, was graded [10] andsubjected to resting ECG. QTc was calculatedby Bazett's formula.[1]

b. Bazett's formula isQTc $=\mathrm{QT} / \sqrt{\mathrm{R}-\mathrm{R} \text { interval }}$

c. QTc of more than $440 \mathrm{msec}$, was considered prolonged.

\section{Results}

The inference of the thumb rule tests indicate the accuracy of the tests, but the same are also the predictor of autonomic neuropathy in diabetic patients.

Table 1: Autonomic neuropathy scoring in different individuals

\begin{tabular}{|l|l|l|l|}
\hline Sl. No & Score & No. of Cases & Percentage (\%) \\
\hline 1. & 2 & 9 & 18 \\
\hline 2. & 3 & 12 & 24 \\
\hline 3. & 4 & 14 & 28 \\
\hline 4. & 5 & 6 & 12 \\
\hline 5. & 6 & 6 & 12 \\
\hline 6. & 7 & 2 & 4 \\
\hline 7. & 8 & 1 & 2 \\
\hline
\end{tabular}

The study showed the maximum cases having a score $4(n=28)$

Table 2: Result of Grading of Autonomic Neuropathy

\begin{tabular}{|l|l|l|l|l|l|}
\hline Grade & I & II & III & IV & Total \\
\hline Type II DM & 21 & 12 & 1 & 7 & 41 \\
\hline Type I DM & 5 & - & - & 4 & 9 \\
\hline Total & 26 & 12 & 1 & 11 & 50 \\
\hline
\end{tabular}

Most of the cases had Grade I Autonomic Neuropathy $(\mathrm{n}=21)$

Table 3: Result of relation between QTc Interval and type of DM

\begin{tabular}{|l|l|l|}
\hline QTc & $<\mathbf{4 4 0}$ & $\mathbf{2 4 0}$ \\
\hline Type II DM & 21 & 20 \\
\hline Type I DM & 6 & 3 \\
\hline Total & 27 & 23 \\
\hline
\end{tabular}

In the study majority of the cases of type II DM had QTc prolonged than 440 mili sec as compared to Type I DM (n=20). 
Table 4: Result of comparison of Relation of Degree of Autonomic Neuropathy with QTc

A) Type II DM:

\begin{tabular}{|l|l|l|l|}
\hline Grade & Total No. of Cases & QTc $\geq \mathbf{4 4 0}$ msec & Percentage \\
\hline I & 21 & - & - \\
\hline II & 12 & 12 & 100 \\
\hline III & 1 & 1 & 100 \\
\hline IV & 7 & 7 & 100 \\
\hline
\end{tabular}

In the study all the patients, belonging to Grade II to IV AN had QTc $\geq 440 \mathrm{msec}$. $(\mathrm{n}=20)$

B) Type I DM:

\begin{tabular}{|l|l|l|l|}
\hline Grade & Total No. of Cases & QTc $\geq \mathbf{4 4 0}$ msec & Percentage \\
\hline I & 5 & - & - \\
\hline II & - & - & - \\
\hline III & - & - & - \\
\hline IV & 4 & 3 & $75 \%$ \\
\hline
\end{tabular}

In the study patients with grade IV AN with prolonged QTc are $03(n=3)$

Table 5: Result of the Relation of Autonomic Score with QTc

\begin{tabular}{|l|l|l|l|l|}
\hline S No. & Score & No. of Cases & QTc $<\mathbf{4 4 0}$ & QTc $\geq \mathbf{4 4 0}$ \\
\hline 1. & 2 & 9 & 9 & - \\
\hline 2. & 3 & 12 & 12 & - \\
\hline 3. & 4 & 14 & 6 & 8 \\
\hline 4. & 5 & 6 & - & $6(100 \%)$ \\
\hline 5. & 6 & 6 & - & $6(100 \%)$ \\
\hline 6. & 7 & 2 & - & $2(100 \%)$ \\
\hline 7. & 8 & 1 & - & $1(100 \%)$ \\
\hline
\end{tabular}

The study showed all the patients with score more than 5 had prolonged QTc $(n=15)$.

Table 6: Relation of Duration of Diabetes Mellitus type II with Autonomic Neuropathy and QTc)

\begin{tabular}{|l|l|l|l|l|l|l|}
\hline $\begin{array}{l}\text { Duration in } \begin{array}{l}\text { Number of } \\
\text { Years }\end{array} \\
\text { cases }\end{array}$ & Grade & I & II & III & QV $\geq 440$ \\
\hline$<5$ & 7 & 7 & - & - & - & \\
\hline $5-10$ & 26 & 13 & 11 & - & 2 & - \\
\hline$>10$ & 8 & 1 & 1 & 1 & 5 & 13 \\
\hline Total & 41 & 21 & 12 & 1 & 7 & 7 \\
\hline
\end{tabular}

The above shows the patients with more than 5 years duration of DM had prolonged QTc $(n=20)$.

Table 7: Relation of diabetes Mellitus with QTc Prolongation

\begin{tabular}{|l|l|l|}
\hline QTc & $<\mathbf{4 4 0}$ & $\mathbf{2 4 0}$ \\
\hline Type II DM & 21 & 20 \\
\hline Type I DM & 6 & 3 \\
\hline Total & 27 & 23 \\
\hline
\end{tabular}

In this study the QTc is prolonged in $46 \%$ of cases $(n=23)$

p-value for Type I DM and Type II DM in for prolonged QTc was 0.08 , which is true. 
The thumb rule tests are cumbersome and need the cooperation and the patient, which is a difficult task, instead a simple ECG can be a predictor of AN in a diabetic patient. The QTc measured was significant in 23 out of 50 Diabetic cases, which infers that the test can be considered as the predictor of autonomic neuropathy if the QTc is more than 440 msec.

\section{Discussion}

Diabetes Mellitus is one of the common diseases. There are several complications of diabetes. The complications get worsened with the duration of Diabetes and with uncontrolled hyperglycemia. Neuropathy is one of the major complications of Diabetes Mellitus. Autonomic neuropathy can be detected by thumb rule tests, which are cumbersome for the patient. A simple bed side ECG test can be performed and the corrected QT (QTc) can be determined which can be an indicator for autonomic neuropathy. The study included 50 diabetic patients. The thumb rule tests were, performed and corrected QT (QTc) was studied.

Out of 50 patients, majority of the patients belonged to age group $41-50$ years and females were more in number. Type II DM were more in prevalence than the type I. Majority of the patients were of more than 5 years duration. Postural dizziness was the commonest symptom in our study whereas the Impotence was the common symptom among the males. Diabetic diarrhoea was the least common, in contrast to Ewing et al 1973 [11].In the symptom ofperipheral neuropathy numbness was the commonest. With the impairment of Deep Tendon Reflexes, Chuttani et al.[12].The study also implicated that when there is a prolongation of QTc [13] the signs of peripheral neuropathy, retinopathy and nephropathy were also observed. Maximum number of the patients with duration of DM more than 5 years and with autonomic score more than 5 had prolonged QTc (>440msec).

\section{Conclusion}

Corrected QT (QTc) interval prolongation has been shown to be an independent predictor of mortality in many clinical settings and is a common finding in hospitalized patients.Instead of doing all the thumb rule tests for autonomic neuropathy, in a diabetic patient, only a simple ECG can be done on the bed-side, by which theQT interval can be calculated. If prolonged (i.e. QTc >440 msec.), this can be a predictor of Autonomic neuropathy, in a Diabetic Patient. The other thumb rule tests can then be performed, to assess the grade of Autonomic Neuropathy.

Funding: Nil

\section{Conflict of interest: Nil \\ Permission from Institutional Research Board (IRB): Yes}

\section{References}

1. Funck-Brentano C, Jaillon P. Rate-corrected QT interval: Techniques and limitations. Am J Cardiol. 1993 Aug 26;72(6):17B-22B.

2. Kahn JK, Sisson JC, Vinik AI. QT interval prolongation and sudden cardiac death in diabetic autonomic neuropathy. J Clin Endocrinol Metab. 1987 Apr;64(4):751-4.

3. Jermendy G, Tóth L, Vörös P, Koltai MZ, Pogátsa G.. Cardiac autonomic neuropathy and QT interval length. A follow-up study in diabetic patients. Acta Cardiol. 1991;46(2):189-200.

4. Bellavere F, Ferri M, Guarini L, Bax G, Piccoli A, Cardone C, Fedele D. Prolongation of QT period in diabetic AN. A possible role in sudden cardiac death. $\mathrm{Br}$ Heart J. 1988 Mar;59(3):379-83.

5.Paul $\mathrm{M}$ et.al: Autonomic dysfunction in patients with arythmogenic right ventricular cardiaomyopathy: biochemical evidence of altered signaling pathway. Pacing Clin Electrophysiol. 2014 Feb;37(2):173-8. Epub 2013 Sep 11

6.Behera D, Das S, Dash RJ, Jindal SK. Cough reflex threshold in diabetes mellitus.Respiration. 1995;62(5):263-8.

7. Wierusz-Wysocka $B^{1}$, Sadurska K, Lukomska E, Dmochowska H. Usefulness of the measurement of corrected QT (QTc) for the diagnosis of diabetic neuropathy of the autonomic cardiovascular system. Pol Tyg Lek. 1992 Jun 1-8;47(22-23):478-9.

8. Rundgren M, Rosén I, Friberg H. AmplitudeIntegrated ECG (a-ECG) predicts outcome after cardiac arrest and induced hypothermia. Intensive Care Med. 2006 Jun;32(6):836-42. Epub 2006 Apr 29. 
9. Ewing DJ, Clarke BF. Diagnosis and management of diabetic autonomic neuropathy. Br Med J 1982; 285:916-8.

10.Lakhotia $\mathrm{M}^{1}$, Shah PK, Vyas R, Jain SS, Yadav A, Parihar MK.: Clinical dysautonomia in Diabetes Mellitus -a study

with seven autonomic reflex function tests . J Assoc Physicians India. 1997 Apr;45(4):271-4.
11. Ewing DJ, Clarke BF. Diagnosis and management of Diabetic autonomic neuropathy. Br Med J (Clin Res Ed). 1982 Oct 2;285(6346):916-8.

12. Chhuttani PN, Chawla LS, Chugh KS, Singh H. Guillain-Barr\&Strohl syndrome in India. J Neurol Sci. 1968 Nov-Dec;7(3):581-92.

13. Viswanath, S, McComb, J.M. et al. QT prolongation in patients withType 2 diabetes and microalbuminuria. Clin Auton Res. 2002;12:366-372.

\section{How to cite this article?}

Kanwar GS, Paikra S, Basan KJ. QTc prolongation - a predictor for autonomic neuropathy in diabetic patients . Int J Med Res Rev 2015;3(6):561-566. doi: 10.17511/ijmrr.2015.i6.106. 